\title{
Extração de incisivo inferior: uma opção terapêutica
}

\author{
Camilo Massa Ferreira Lima*, Eduardo Lacet**, Candice Ramos Marques ${ }^{\star \star \star ~}$
}

\begin{abstract}
Resumo
O planejamento ortodôntico em casos de apinhamento, normalmente oscila entre não extração e extrações de quatro pré-molares. Em determinadas situações a escolha por uma alternativa ou outra pode provocar conseqüências negativas. A extração de um incisivo inferior em casos bem selecionados é uma abordagem eficiente, pouco explorada na literatura. Entretanto, para sua correta indicação o ortodontista precisa conhecer as variáveis que envolvem este tipo de terapia. O objetivo deste trabalho é abordar de maneira sistemática os diversos aspectos clínicos relacionados com esta modalidade terapêutica, ilustrando sua aplicabilidade com a apresentação de casos clínicos.
\end{abstract}

Palavras-chave: Apinhamento. Extração de incisivo inferior. Diagnóstico

\section{INTRODUÇÃO}

A alta prevalência de apinhamentos dentários coloca os ortodontistas frente a um constante dilema: extração x não extração. Esse embate secular travado por Angle e Case ${ }^{2}$ não mais procede em tempos atuais. A questão não é seguir uma corrente extracionista ou expansionista. A decisão por uma conduta ou outra deve estar baseada em alguns aspectos: discrepância total (discrepância de modelo, discrepância cefalométrica e curva de Spee), perfil da face, relação sagital das bases ósseas e padrão facial ${ }^{8,13}$.

Segundo Janson et al. ${ }^{5}$, a extração de pré-molares em tratamentos ortodônticos pode levar, em determinadas situações, ao achatamento do perfil facial, agravado pelas alterações faciais decorren- tes da idade. Por outro lado, o tratamento sem extrações pode promover a falta de selamento labial, recessões gengivais e maior tendência à recidiva.

A extração de um incisivo inferior poderia ser uma opção terapêutica bastante eficaz em casos criteriosamente selecionados. Em situações borderline ela seria uma alternativa intermediária entre os dois extremos citados acima.

Em virtude da pouca atenção dispensada a esta modalidade de tratamento, o presente trabalho tem como finalidade ressaltar alguns aspectos a serem avaliados para uma correta indicação, comentar suas vantagens e desvantagens e abordar algumas características peculiares da mecânica ortodôntica aplicada, ilustrado com a apresentação de casos clínicos.

* Especialista em Ortodontia e Ortopedia Facial pela FOP. Professor do Centro de Aperfeiçoamento Odontológico de PernambucoODONTOCAPE

** Especialista em Ortodontia e Ortopedia Facial pela FOP. Professor do Centro de Aperfeiçoamento Odontológico de PernambucoODONTOCAPE

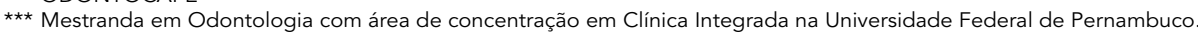




\section{INDICAÇÕES E CONTRA-INDICAÇÕES}

A melhor indicação para essa abordagem constitui-se na má oclusão de Classe I, com apinhamento ântero-inferior que se aproxime das dimensões de um incisivo inferior, com dentição superior normal e intercuspidação perfeita ${ }^{1}$.

Para Owen ${ }^{10}$, os requisitos necessários para se indicar a terapia com extração de um incisivo são: relação molar de Classe I, apinhamento inferior moderado, apinhamento superior leve ou inexistente, perfil mole equilibrado, overjet e overbite mínimos ou moderados.

Outra indicação ${ }^{13}$ seria casos de Classe II leves, onde a discrepância de modelos seja menor que o tamanho do incisivo, valendo-se do espaço remanescente para correção da chave de canino.

Alguns autores ${ }^{3,4}$ recomendaram esta opção terapêutica em pacientes adultos Classe III leve a moderada com overjet e overbite reduzidos. Anomalia de número dos dentes anteriores, alterações de tamanho dentário e incisivos ectópicos também são citados como indicações para essa mecânica ${ }^{3}$. Kokich ${ }^{7}$ destacou ainda, os casos em que esses dentes sofreram traumas ou apresentam cáries severas.

Situações em que o overjet é excessivo representam a principal contra-indicação para a remoção de um incisivo ${ }^{3,10}$. Segundo Bahreman ${ }^{1}$, também constituem contra-indicações: casos com apinhamento bimaxilar sem discrepância no tamanho dentário na região anterior, más oclusões com relação de Classe I de canino que requerem extrações de primeiros pré-molares superiores, discrepância de Bolton com incisivos inferiores pequenos ou superiores grandes e pacientes com overbite profundo e padrão de crescimento horizontal. Valinoti ${ }^{13}$ discordou quanto a esta última afirmação, alegando que o controle adequado do overbite viabilizaria a mecânica com exodontia de incisivos.

Nota-se, portanto, que em situações bem selecionadas a extração de um incisivo inferior pode ser utilizada em casos de Classe I, II ou III.

\section{CONSIDERAÇÕES CLÍNICAS}

Durante o planejamento ortodôntico de casos com apinhamento, algumas mensurações como a discrepância de modelos, cefalométrica e curva de Spee, fornecem subsídios numéricos para a decisão do caminho a ser seguido ${ }^{13}$.

Outra avaliação que merece destaque é a quantificação da discrepância de Bolton ${ }^{1,4,7,13}$. Segundo Kokich ${ }^{7}$, discrepâncias acima de 1,6 mm são consideradas significativas, indicando a extração de incisivos em excesso mandibular acima de $2 \mathrm{~mm}$. Bahreman ${ }^{1}$, por sua vez, prefere adotar o percentual da relação entre os dentes ânteroinferiores e os ântero-superiores como parâmetro de avaliação, estabelecendo o valor acima de 83\% como bom indicativo. Se a análise de Bolton apresentar um percentual aumentado e a origem desse valor for incisivos superiores com diâmetro mesiodistal reduzido a ponto de comprometer a estética, o procedimento eleito é o restabelecimento anatômico destes com a Odontologia cosmética $^{7}$. Entretanto, se houver excesso inferior significativo, duas alternativas podem ser escolhidas: exodontia de um incisivo ou stripping dos incisivos.

De acordo com alguns autores ${ }^{4,7}$ a avaliação anatômica da coroa dos incisivos inferiores é fundamental. Apinhamentos leves a moderados em incisivos com coroas de formato triangular poderiam ser bem resolvidos por meio de desgastes interproximais, favorecendo a estética pela preservação das papilas gengivais.

Critério, bom senso e cautela são fundamentos que um bom ortodontista deve trazer consigo. Baseado nesses princípios, alguns autores ${ }^{10,13}$ acreditam que fórmulas de tamanho dentário não são suficientemente precisas para prever a oclusão final. Para eles o setup do caso é fundamental para visualizar a finalização, determinando, por exemplo, numericamente a quantidade de desgastes interproximais a serem realizados nos incisivos superiores para uma correta intercuspidação. 
A distância intercaninos normal é outro importante ponto a ser avaliado ${ }^{4}$. A manutenção desta distância durante a mecânica com extração de incisivos é vantajosa quando comparado à de pré-molares e está muito relacionada à estabilidade pós-tratamento ${ }^{13}$.

\section{ESCOLHA DO INCISIVO}

Alguns aspectos devem ser considerados para definir qual incisivo será extraído ${ }^{1}$, entre eles: quantidade de deficiência de espaço; discrepância de Bolton; relação entre a linha média superior e inferior, e saúde periodontal, indicando a extração do incisivo mais ectópico ${ }^{3}$. Valinoti ${ }^{13}$ relatou que na grande maioria dos casos escolhe o incisivo central.

\section{ÉPOCA DE TRATAMENTO}

"Depois de usar o fórceps, não há possibilidade de retorno" ${ }^{\prime}$. Esta frase retrata a seriedade da indicação da remoção de um dente permanente. Esta decisão, especialmente no caso de um incisivo, deve ser adiada até o momento de dentadura permanente jovem ${ }^{13}$. Owen ${ }^{10}$ aconselha decidir sobre esta extração quando houver um potencial mínimo de crescimento, visando não alterar a relação incisal estabelecida precocemente.

\section{FINALIZAÇÃO}

Ao considerarmos que a nova situação oclusal irá promover articulação de seis dentes superiores com cinco inferiores, muitos autores ${ }^{12,13}$ destacam que é plenamente possível alcançar excelente relação incisal através de controle do overbite e redução do overjet por meio de desgastes interproximais dos incisivos superiores.

Entretanto, Kokich ${ }^{7}$ ressaltou importantes características a serem avaliadas em relação ao stripping superior antes da decisão de se extrair um incisivo. Os incisivos superiores que apresentam a forma de sua coroa anatômica tendendo a triangular são mais favoráveis ao desgaste interproximal. A largura da raiz, determinada em uma radiografia periapical, se for aumentada na sua porção cervical, não permite grande redução da coroa pelo risco da proximidade radicular. Outra questão diz respeito à quantidade de esmalte interproximal, também quantificado em radiografia periapical, prevenindo exposição dentinária. O último fator é a inclinação de ambos os incisivos. Se os inferiores estiverem lingualizados, permite-se uma projeção para diminuição do overjet. No entanto, quando os superiores estiverem verticalizados é um indício de que não se pode contar com a redução de seu diâmetro mesiodistal, uma vez que tal procedimento resultaria em incisivos ainda mais retro-inclinados.

Vale salientar e informar ao paciente que ao final do tratamento a linha média superior irá coincidir com o meio do incisivo central inferior. Tal situação não leva a nenhum comprometimento estético ${ }^{6,13}$.

\section{ESTABILIDADE}

De acordo com Valinoti ${ }^{13}$, existe uma forte relação entre estabilidade de correção de apinhamentos e a distância intercaninos. Acreditase que pelo fato do tratamento com exodontia de um incisivo manter esta distância ou até diminuí-la, antecipando um futuro decréscimo natural, traria melhor estabilidade para o resultado final.

Os estudos de Riedel, Little, Bui ${ }^{11}$ e Canut ${ }^{3}$ sugerem que a simples manutenção ou redução da distância intercaninos durante o tratamento não garante estabilidade total a longo prazo, mas contribui para um menor grau de recidiva quando comparado aos casos tratados com extrações de pré-molares. Recomenda-se ainda, como estratégia para minimizar recidivas, a remoção do incisivo mais ectópico ${ }^{3}$.

\section{VANTAGENS E DESVANTAGENS}

Dentre os efeitos indesejáveis da mecânica com extração de um incisivo, Faeroving e Zachrison ${ }^{4}$ 
destacaram a perda anti-estética da papila interdentária, aumento do overjet e overbite acima do aceitável, oclusão posterior insatisfatória e recorrência do apinhamento nos dentes remanescentes.

A perda anti-estética da papila ocorre em situações onde a coroa dos incisivos possuem conformação triangular. Nestes casos, talvez a melhor abordagem para correção do apinhamento fosse o stripping dos incisivos inferiores.

Com relação ao aumento do overjet e overbite, em casos bem selecionados, ou seja, com essas medidas reduzidas, poderia ser considerado um aspecto vantajoso. Além disso, existem recursos mecânicos de controle vertical e a opção de um stripping superior para diminuição do overjet remanescente.

No que diz respeito à oclusão posterior, vale salientar que uma das melhores indicações para este tipo de tratamento é a Classe I com intercuspidação perfeita e falta de espaço de magnitude semelhante ao diâmetro de um incisivo. É uma questão de critério na seleção dos casos. Os casos clínicos apresentados neste artigo ajudam a avaliar esse item.

Quanto à instabilidade pós-tratamento, talvez não possa ser considerada desvantagem. É difícil afirmar até que ponto o apinhamento recorrente seria considerado recidiva (bem menor que as amostras de extrações de pré-molares) ou apenas parte de um processo evolutivo natural presente, inclusive, em pacientes não tratados.

Comenta-se ainda sobre a possibilidade de reabertura do espaço, resultando em desagradável diastema anterior ${ }^{3,4}$. Esse problema poderia ser minimizado ou resolvido através da obtenção de paralelismo radicular ao final do tratamento.

A inconveniência, em curto prazo, causada pela extração de um dente anterior e a ausência de linha média inferior, ao término do tratamento, devem ser comentados com o paciente e, na grande maioria dos casos, não compromete a estética final.

Canut $^{3}$ aponta ainda como limitação desta abordagem, a tendência de mesialização dos caninos inferiores, comprometendo essa guia nos movimentos de lateralidade. Foi citado anteriormente que em casos de leve Classe II de caninos, tal situação poderia ser considerada uma indicação para colocar estes dentes em chave. Outro ponto a ser considerado é que dependendo da quantidade de discrepância dente-osso, o espaço criado pode ser totalmente utilizado para resolver o apinhamento, sem movimento dos dentes posteriores.

O planejamento ortodôntico com exodontia de um incisivo apresenta como principais vantagens a redução considerável do tempo de tratamento, uma vez que o dente removido encontra-se próximo ao problema, além da simplicidade mecânica, traduzida em pouca preocupação com ancoragem e manutenção da distância intercaninos ${ }^{1,3,6}$.

\section{DESCRIÇÃO DOS CASOS CLÍNICOS}

\section{Caso clínico 1}

A paciente I. F. S., 18 anos, apresentava queixa estética quanto ao mal posicionamento dos dentes. Ao exame clínico e de modelos observou-se uma relação dentária de 1/4 de Classe II subdivisão direita, overjet normal, overbite profundo e retração gengival no elemento dentário 43 (Fig. 1.1 - 1.3). A discrepância de modelos inferior foi de $-5 \mathrm{~mm}$ (Fig. 1.4) e superior de -2 $\mathrm{mm}$ e a análise de Bolton anterior indica excesso de massa dentária inferior de $1,1 \mathrm{~mm}$. A análise cefalométrica mostra uma relação esquelética sagital de Padrão I $\left(A N B=3^{\circ}\right)$ e um tipo facial dolicocefálico (SN.GoGn $=39,5^{\circ}$ ) (Fig. 1.5). A face, biprotrusa, apresentava terço inferior aumentado e ausência de selamento labial passivo (Fig. 1.6 - 1.8).

Considerando a característica de biprotrusão, padrão facial, discrepância de modelos e posicionamento dos incisivos inferiores em suas bases ósseas, o plano de tratamento proposto e recusado pela paciente foi de extração dos quatro 

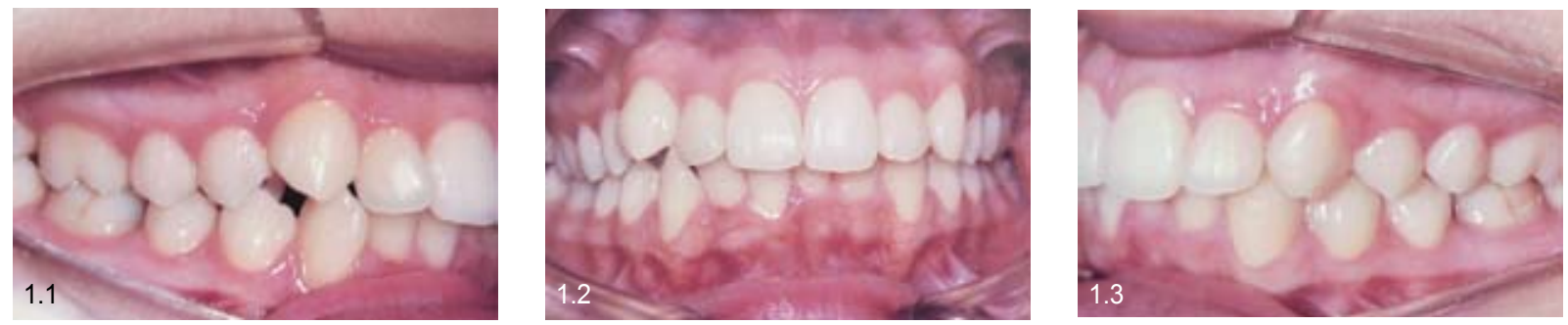

FIGURAS 1.1, 1.2 e 1.3 - Fotografias intrabucais iniciais.

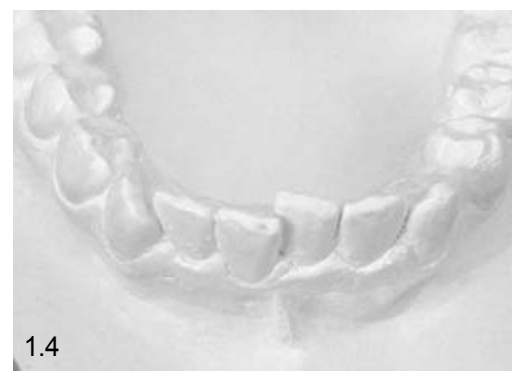

FIGURA 1.4 - Apinhamento visto no modelo de estudo inicial.

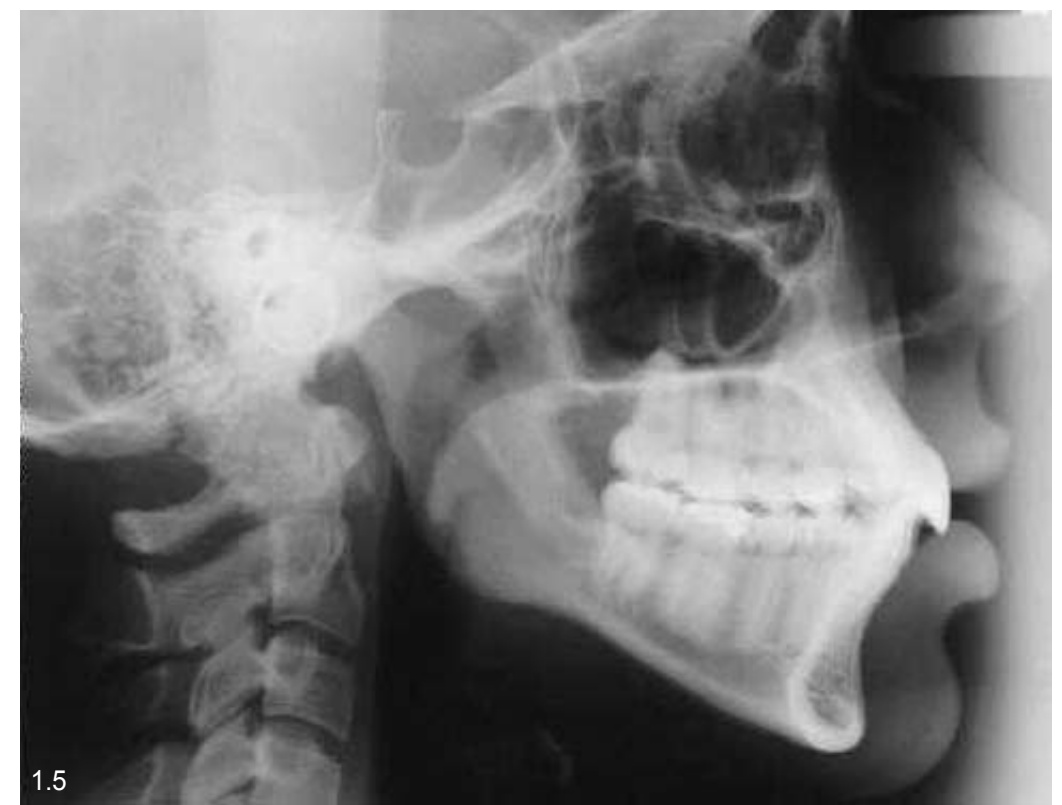

FIGURA 1.5 - Telerradiografia em norma lateral inicial.
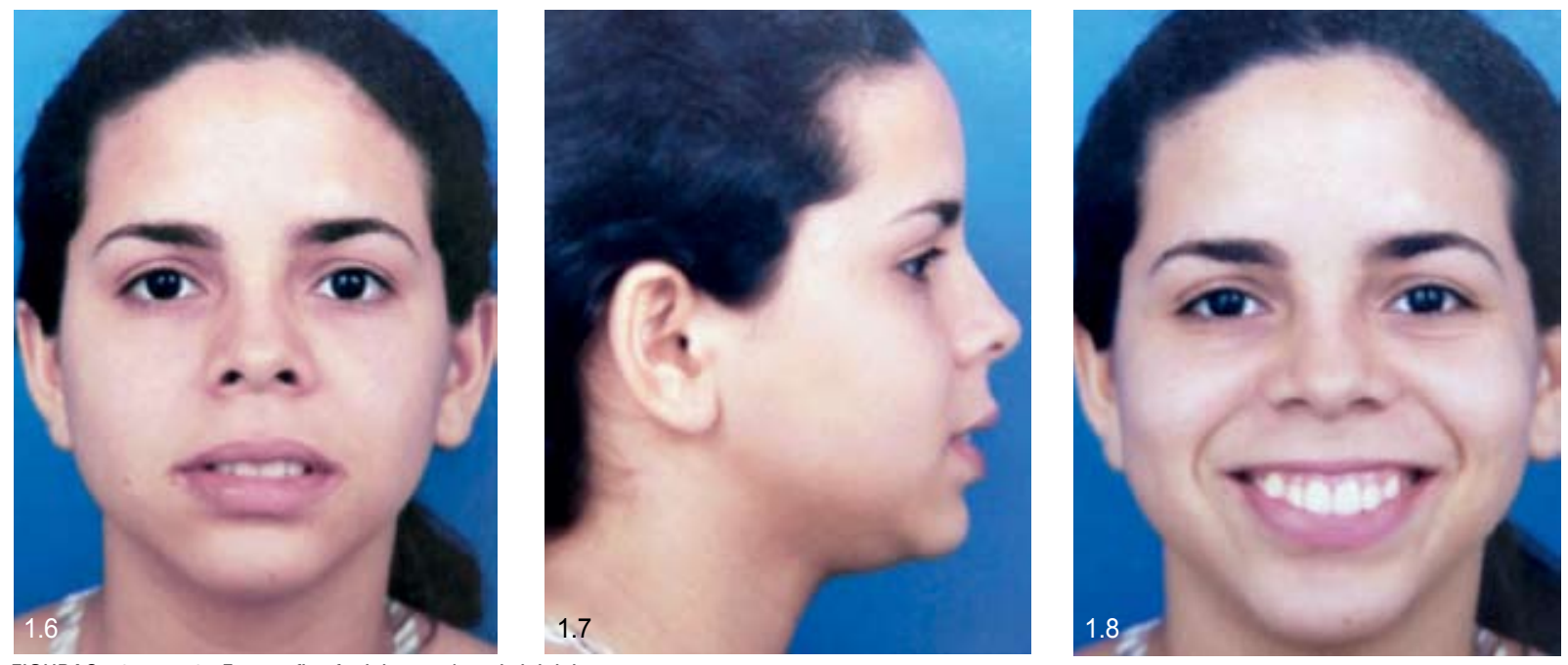

FIGURAS 1.6, 1.7, 1.8 - Fotografias faciais extrabucais iniciais. 


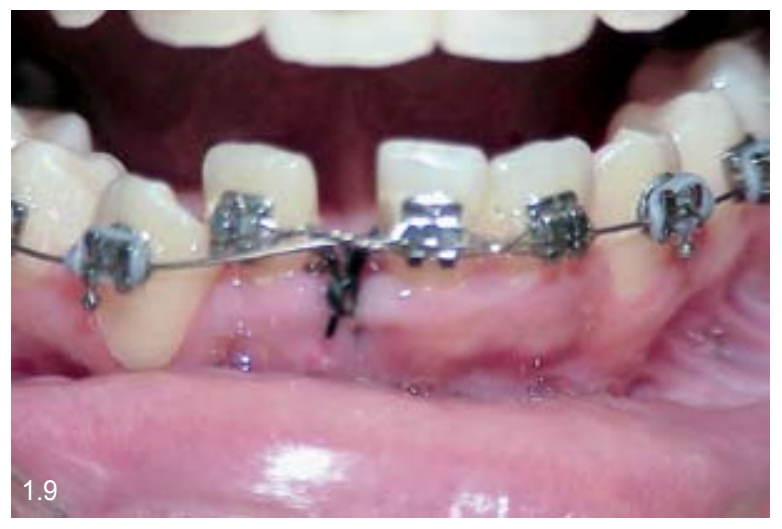

FIGURA 1.9 - Início do fechamento de espaço, poucos dias após exodontia.
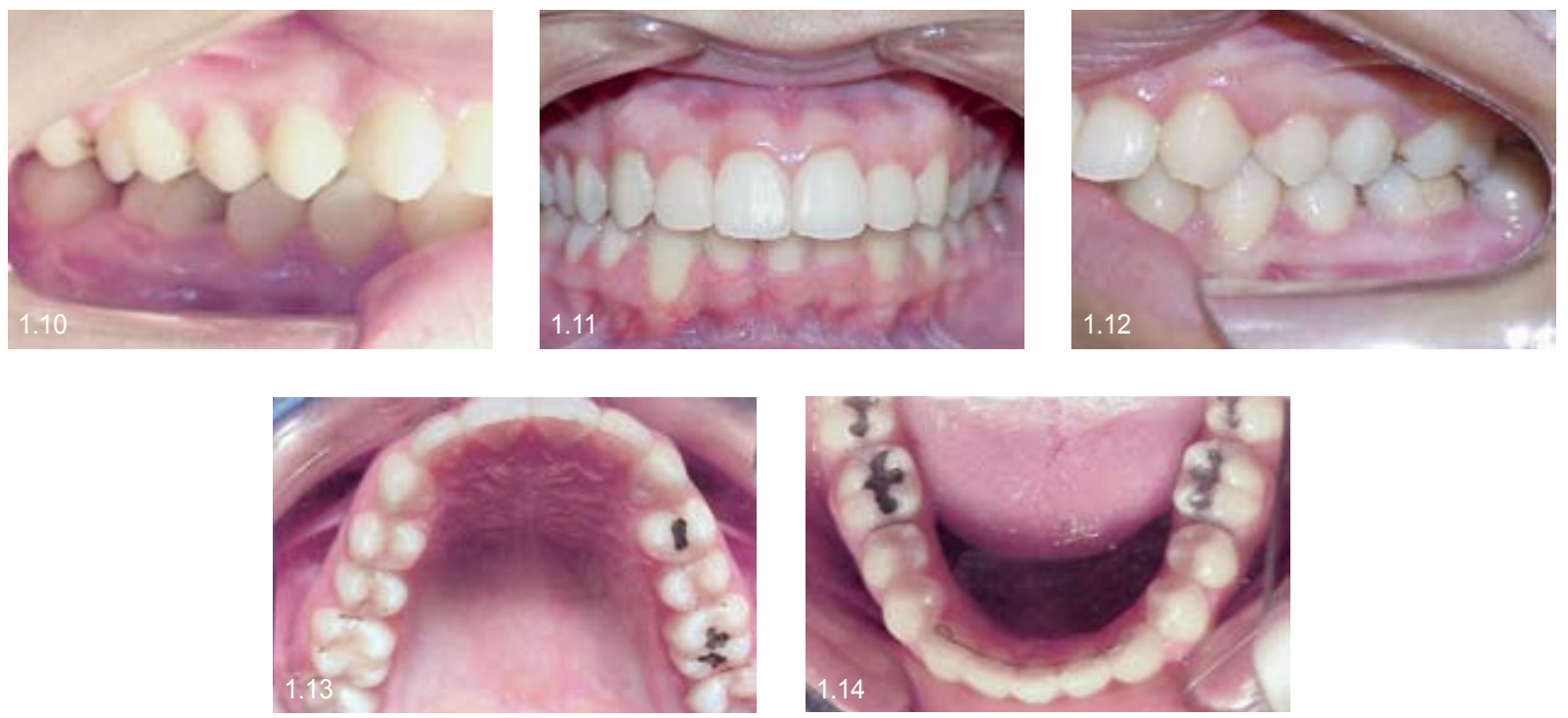

FIGURAS 1.10, 1.11, 1.12, 1.13 e 1.14 - Fotografias intrabucais finais.

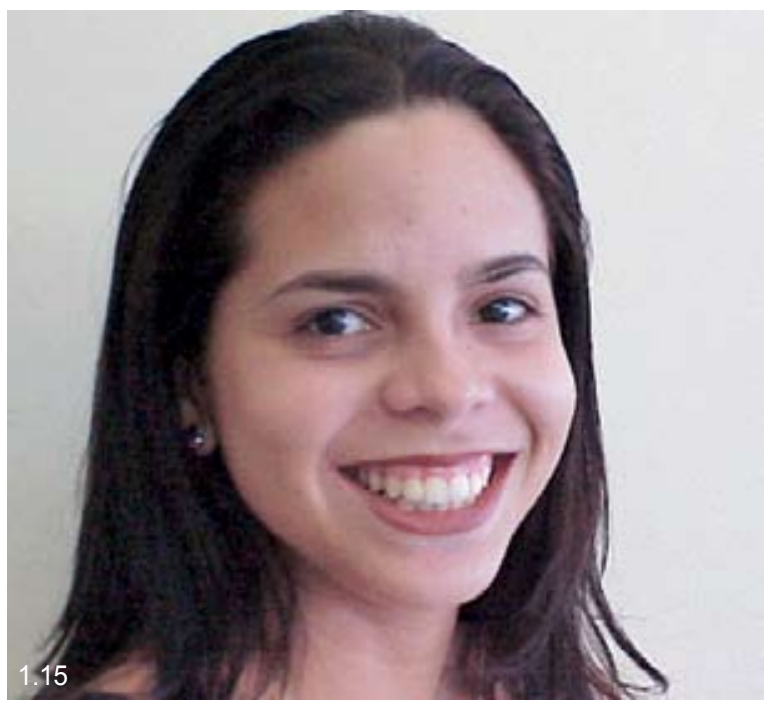

FIGURA 1.15 - Fotografia do sorriso final. 
primeiros pré-molares. Como alternativa viável para o caso, foi sugerida a remoção do elemento dentário 41, escolhido pelo menor tamanho, posicionamento e retração gengival (Fig. 1.9). O apinhamento superior e a discrepância de Bolton, criada pela exodontia do incisivo inferior, seriam resolvidos com desgastes interproximais. As características faciais, por desejo da paciente seriam mantidas.

O resultado final atende à queixa principal da paciente, com obtenção de um bom alinhamento dentário e excelente intercuspidação (Fig. 1.10 - 1.14). Não se observam mudanças no aspecto facial, conforme foto sorrindo (Fig. 1.15). A retração gengival do elemento 43 manteve-se constante, sem repercussão estética para o sorriso.

\section{Caso clínico 2}

A paciente M.B.M., 30 anos, nos procurou com o objetivo de realizar um retratamento ortodôntico. Ao exame clínico constatou-se a abertura de diastemas bilaterais significativos entre os caninos e segundos pré-molares superiores. $\mathrm{O}$ arco inferior apresentava uma discrepância de modelos de 3,5 mm com o elemento dentário 41 posicionado ectopicamente (Fig. 2.1 - 2.7). Após a realização de um setup de modelos, foi proposto o tratamento ortodôntico com extração de um incisivo inferior.

Devido ao comprometimento estético da remoção de um elemento dentário anterior, sem possibilidade de colocação de um dente provisório em função do pequeno espaço remanescente, solicitamos a sua exodontia somente após a montagem de todo aparelho (Fig. 2.8 - 2.10). A presença dos acessórios além de ser um indicativo de que o indivíduo com aquela ausência encontrava-se em tratamento ortodôntico, não se perdeu tempo com a montagem do aparelho após a extração. O espaço começou a ser fechado logo após a cicatrização do processo cirúrgico.

Durante a montagem do aparelho, seguindo os preceitos da técnica Straight Wire, contra- angulamos os braquetes dos dentes adjacentes (Fig. 2.11) para que já no primeiro fio de nivelamento, nitinol .016", pudéssemos iniciar o fechamento de espaço com a ativação de um "lace back", resultando em movimento de translação ao invés de só inclinação de coroa. No fio intermediário, aço inoxidável .018", posicionamos os acessórios corretamente e solicitamos radiografias (Fig. 2.12 e 2.13) para constatarmos o paralelismo radicular. Foi utilizado stripping na região ântero-superior para obtenção de overjet adequado pela verticalização dos incisivos superiores. Ao final, a paciente fez uso de Odontologia cosmética para restabelecimento da anatomia dental desgastada pelo hábito de bruxismo.

O resultado final (Fig. 2.14 - 2.21) mostra uma relação de Classe I de caninos, linha média superior coincidindo com o meio do incisivo central inferior, bom alinhamento e nivelamento e ausência de diastemas.

\section{Caso clínico 3}

A paciente C.M.R.S., 21 anos, outro retratamento ortodôntico, apresentava ausência do elemento dentário 46, arco superior sem apinhamento e inferior com $4 \mathrm{~mm}$ de falta de espaço (Fig. 3.3 - 3.7). No exame dos modelos observouse uma relação de canino direito de $1 / 4$ de Classe II, overjet e overbite diminuídos. $\mathrm{Na}$ análise cefalométrica constatou-se uma relação basal de $\mathrm{Pa}$ drão I $\left(A N B=3,5^{\circ}\right)$ com incisivos superiores e inferiores bem posicionados em suas bases ósseas $\left(1 . \mathrm{NA}=18^{\circ} ; 1-\mathrm{NA}=5 \mathrm{~mm} ; \mathrm{IMPA}=86,5^{\circ}\right.$ ) (Fig. 3.8). A face, apesar da biprotrusão, ao exame clínico apresentava selamento labial passivo (Fig. 3.1, 3.2). O planejamento ortodôntico incluiu a extração do elemento dentário 41.

O espaço criado foi utilizado para resolver o apinhamento e mesialização dos dentes 43,44 e 45 , melhorando a chave de canino e aumentando o espaço protético destinado ao 46. Com o espaço remanescente foi melhorado o pequeno overjet e overbite (Fig. 3.9 - 3.11). 

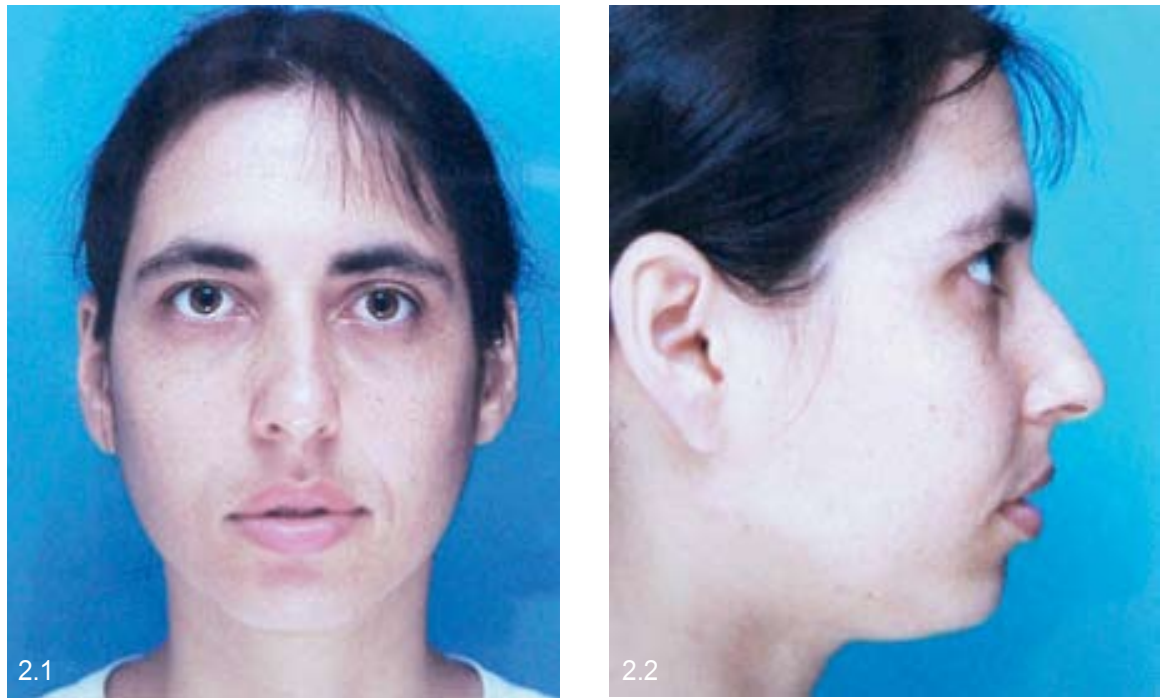

FIGURAS 2.1 e 2.2 - Fotografias faciais extrabucais iniciais.
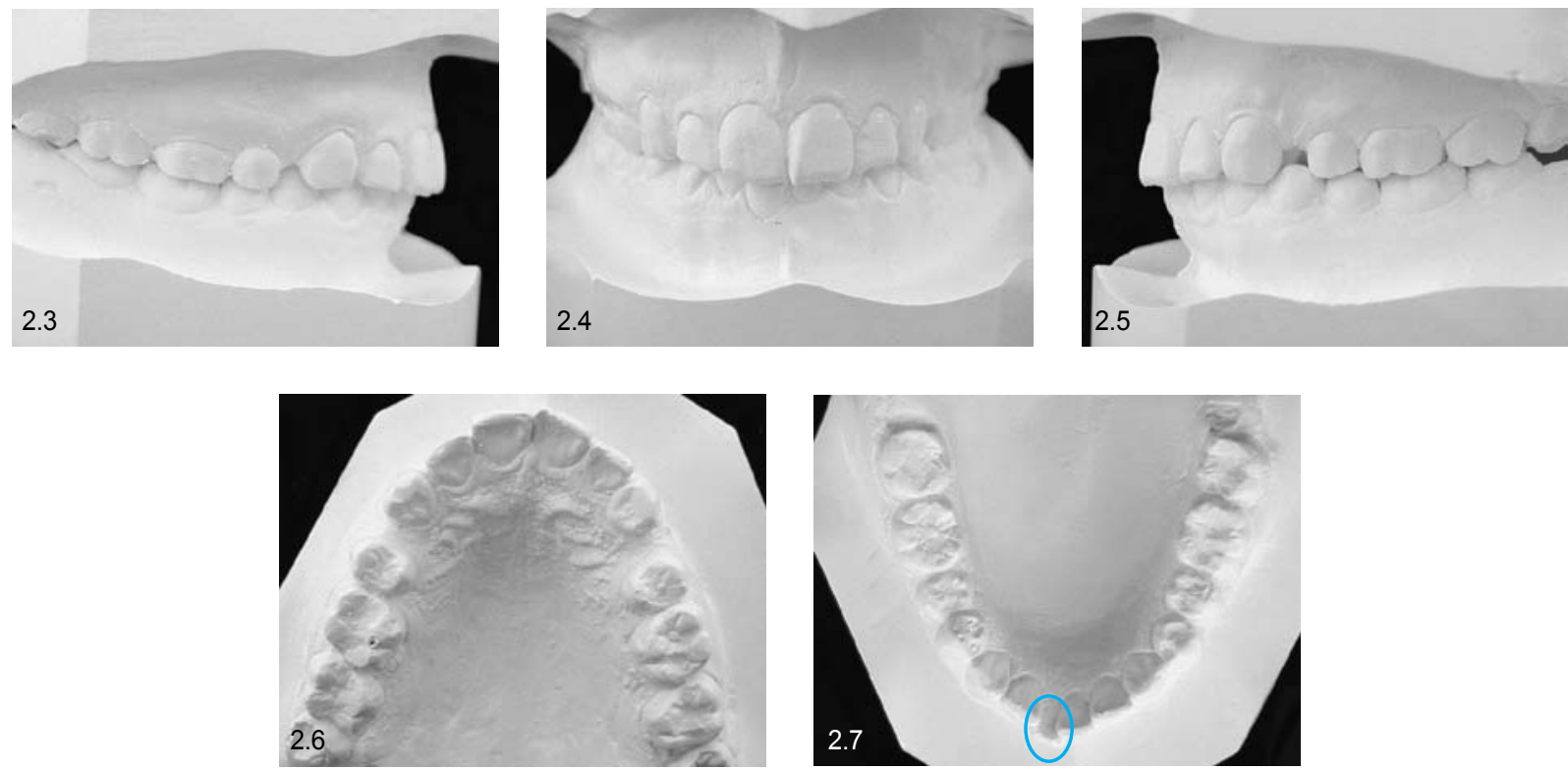

FIGURAS 2.3, 2.4, 2.5, 2.6 e 2.7: Modelos de estudo iniciais, mostrando os espaços superiores e posicionamento ectópico do elemento dentário 41.
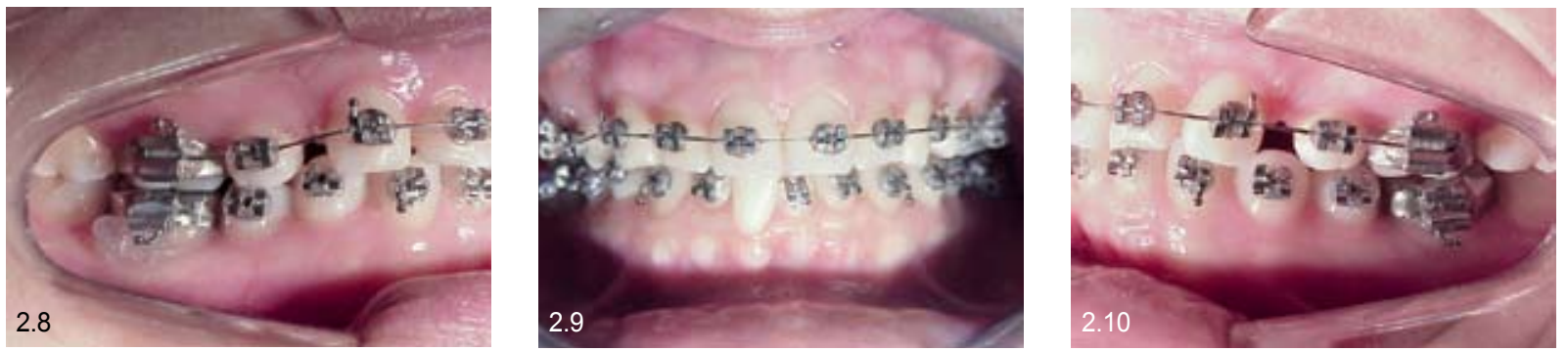

FIGURAS 2.8, 2.9 e 2.10 - Montagem do aparelho excluindo o elemento dentário 41 


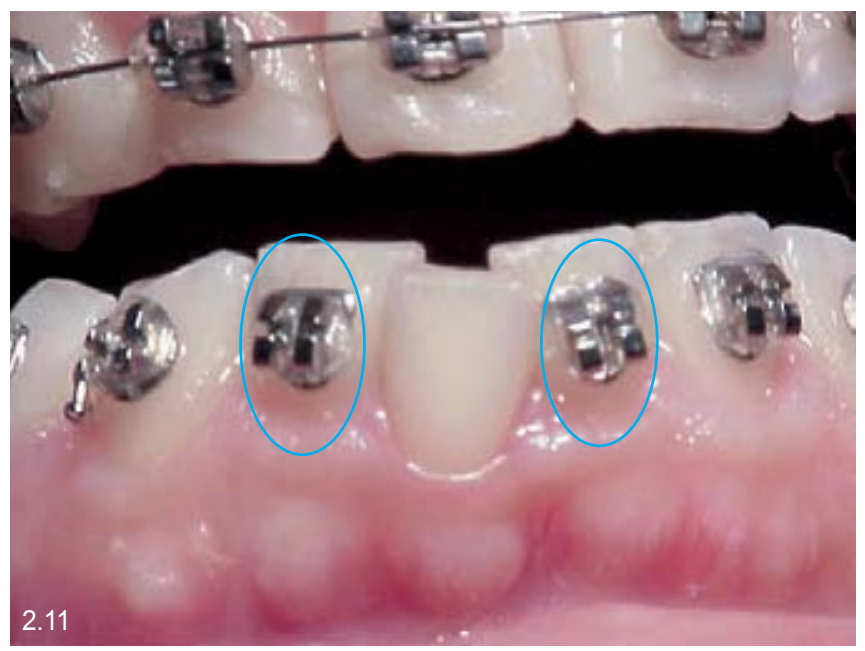

FIGURAS 2.11 - Detalhe da contra-angulação dos braquetes dos dentes adjacentes.
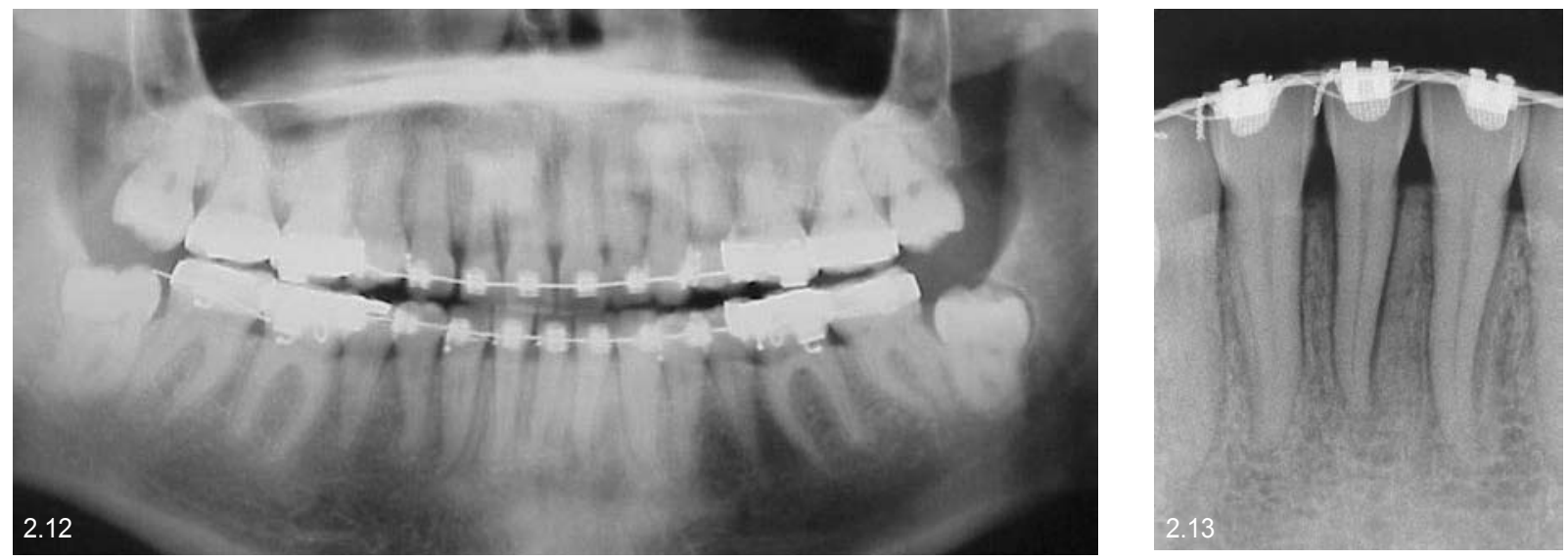

FIGURAS 2.12 e 2.13 - Radiografia panorâmica e periapical, logo após o fechamento de espaço e posicionamento correto dos acessórios do dente 31 e 42 , evidenciando o paralelismo radicular.
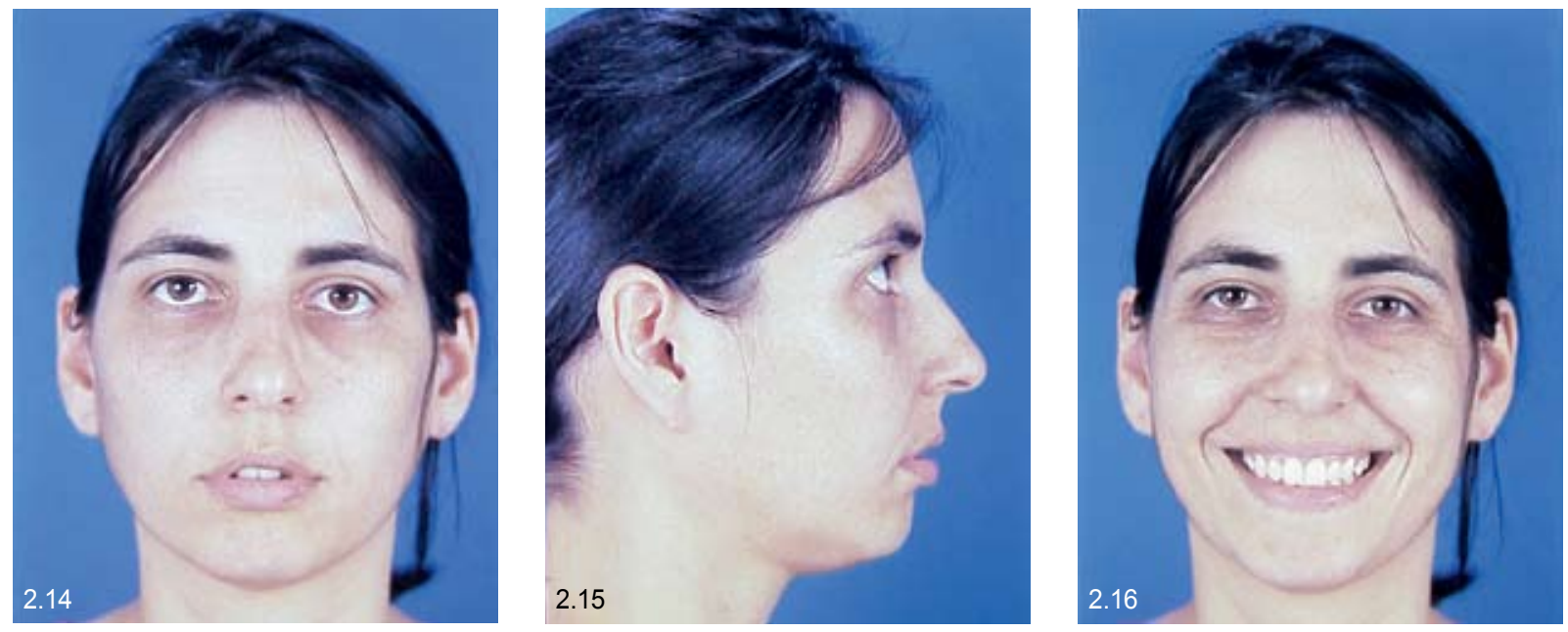

FIGURAS $2.14,2.15$ e 2.16 - Fotografias faciais extrabucais finais. 

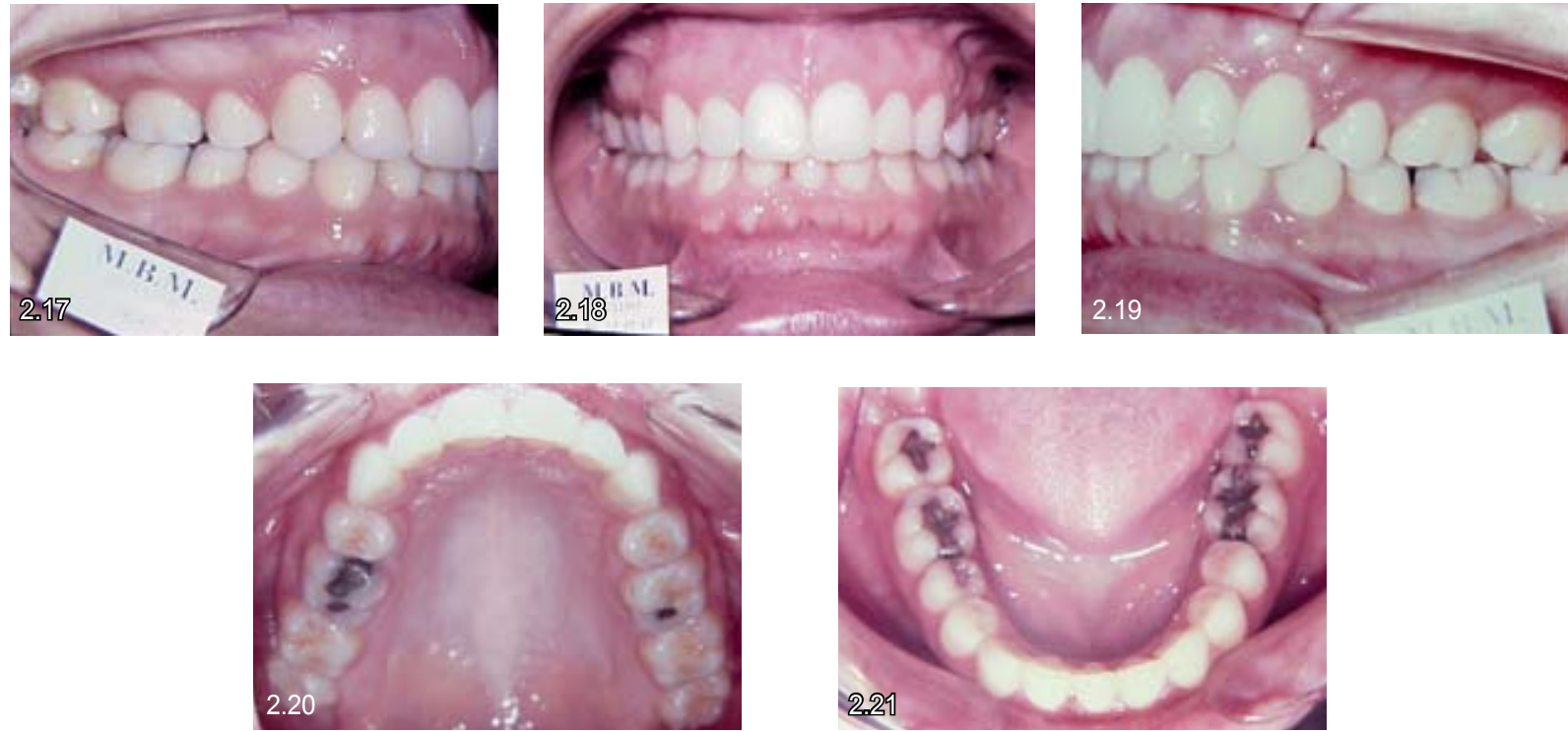

FIGURAS $2.17,2.18,2.19,2.20$ e 2.21 : Fotografias intrabucais finais.

Durante a mecânica Edgewise, foram utilizadas dobras no arco inicial de aço inoxidável .014" (seguindo os preceitos da técnica) para fechamento imediato do espaço com movimento de corpo dos dentes adjacentes (Fig. 3.12 - 3.15). Vale salientar ainda a utilização de alça de verticalização dos molares com fio TMA, apoiado

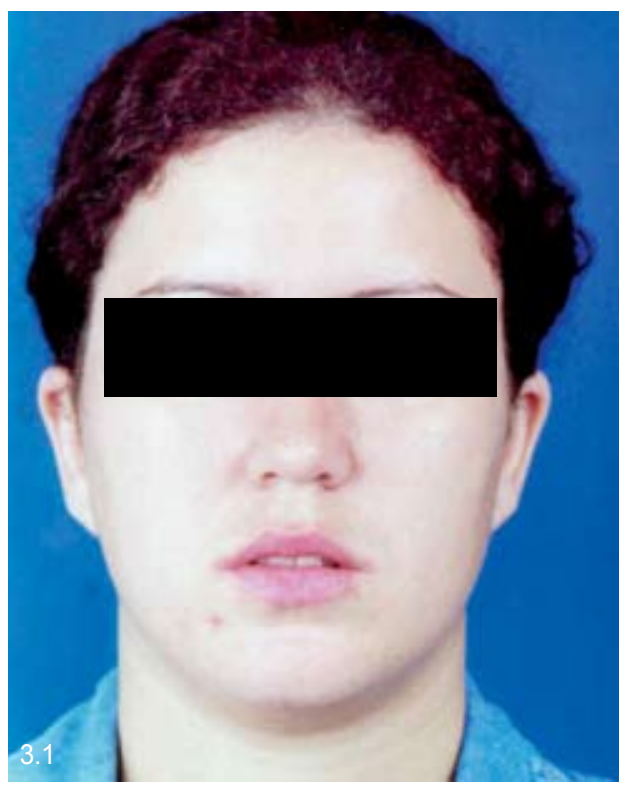

FIGURAS 3.1 e 3.2 - Fotografias faciais extrabucais inicias. no tubo de Marcote, fixado ao arco .019"x .025" (Fig. 3.16, 3.20). Na fase de finalização foram utilizados elásticos intermaxilares para aumento do overbite (Fig. 3.24).

As fotografias finais não estão presentes pelo fato da paciente ainda se encontrar em tratamento.

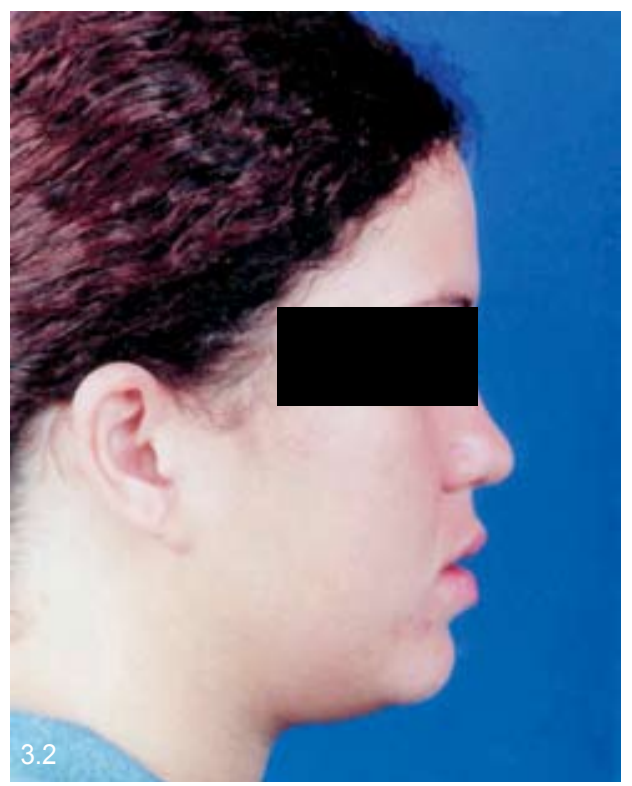



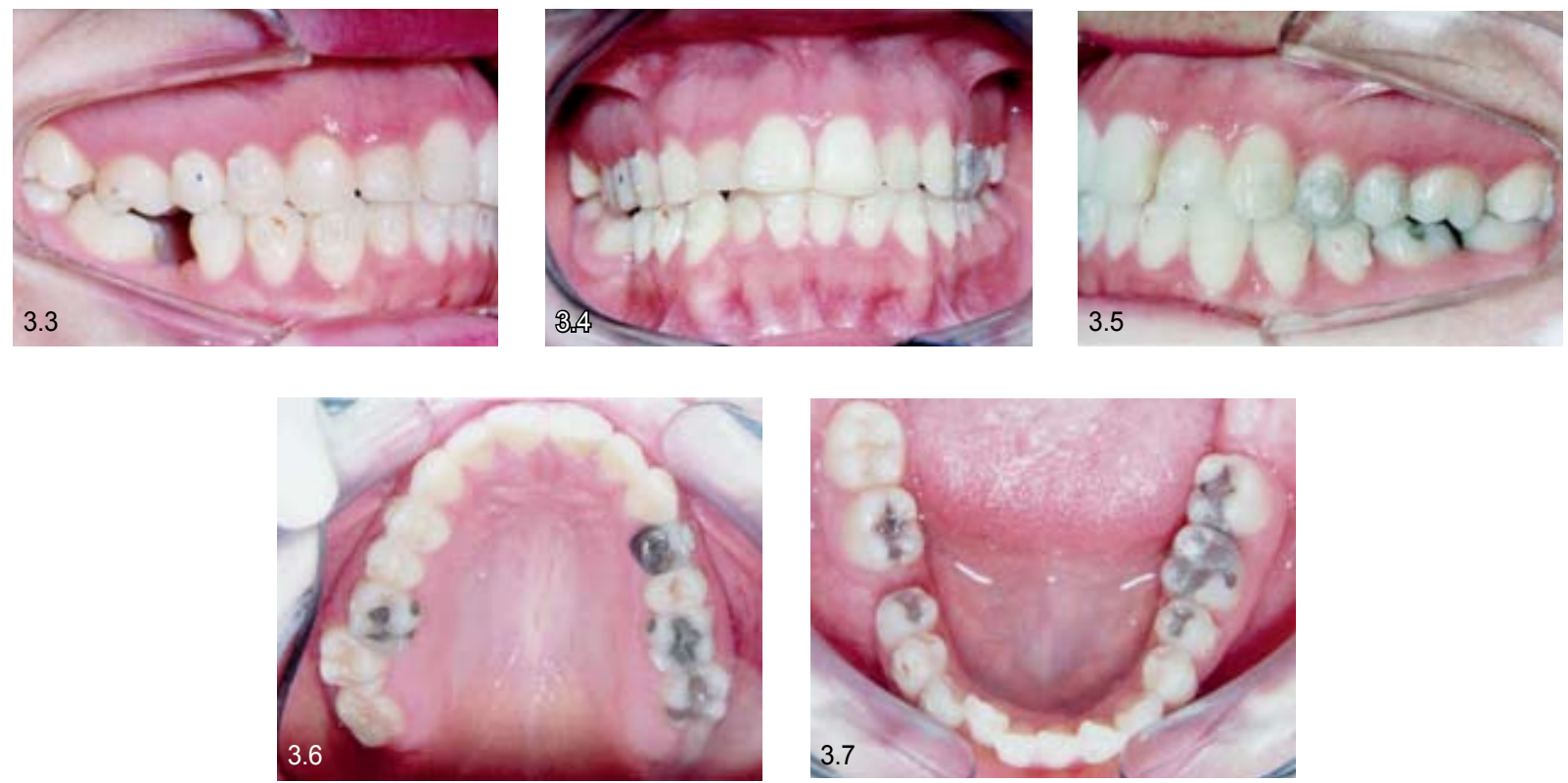

FIGURAS 3.3, 3.4, 3.5, 3.6 e 3.7 - Fotografias intrabucais iniciais.

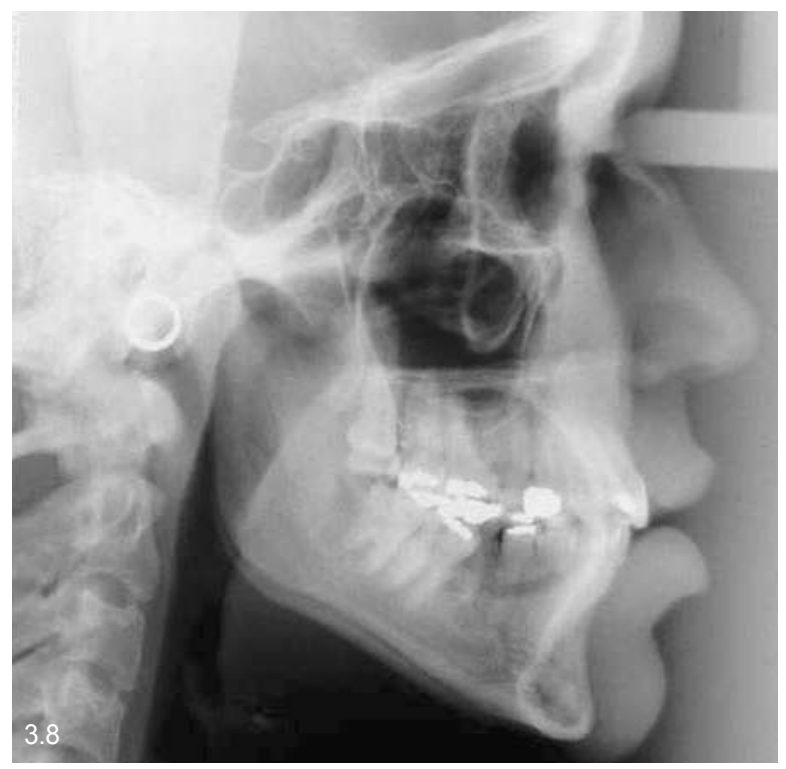

FIGURAS 3.8 - Telerradiografia em norma lateral inicial.
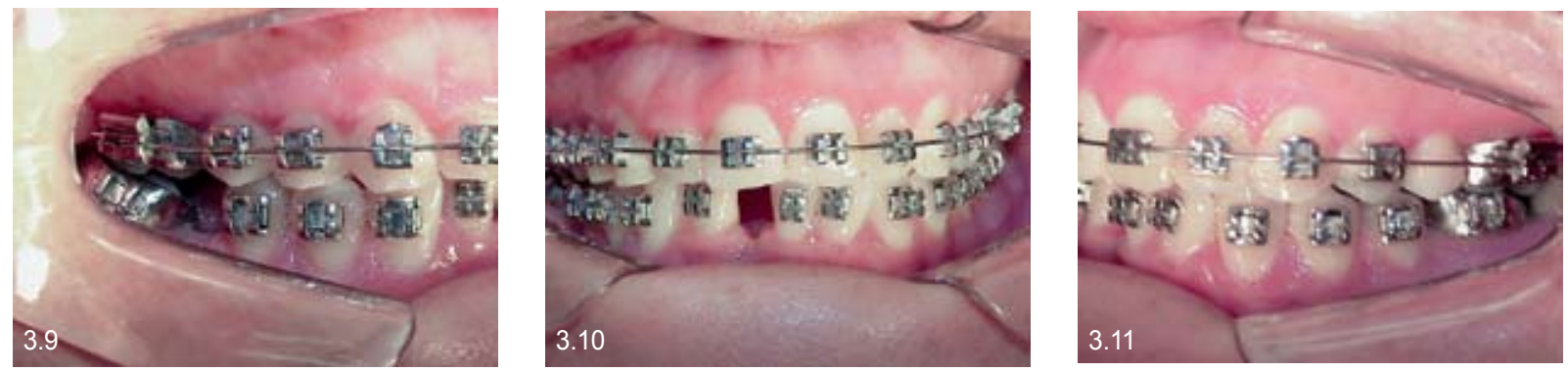

FIGURAS 3.9, 3.10 e 3.11 - Fotografias intrabucais após exodontia do dente 41. 

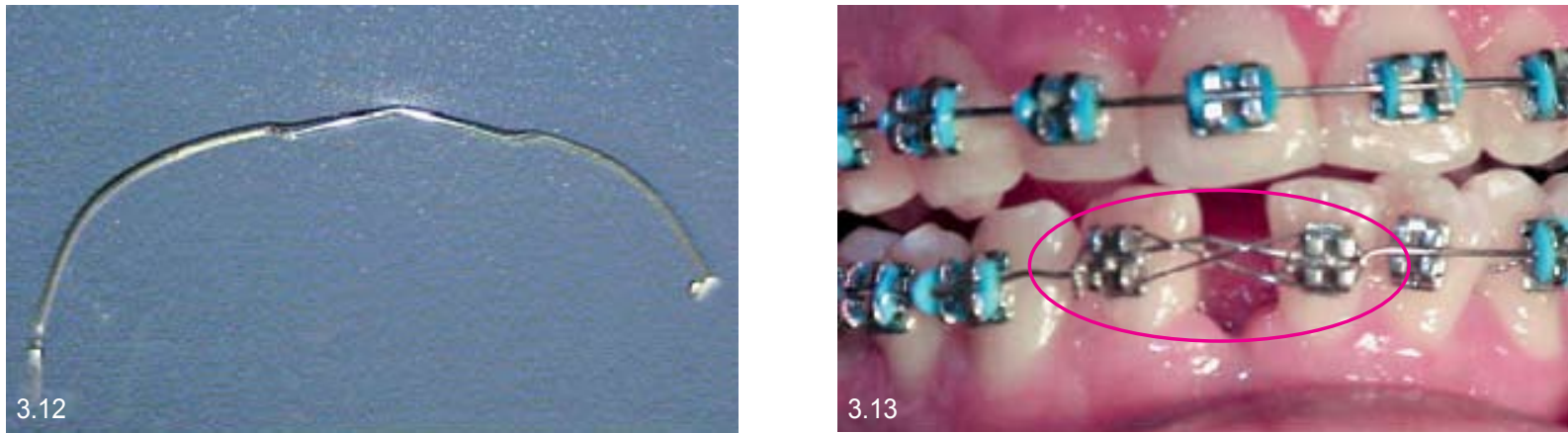

FIGURAS 3.12 e 3.13 - Detalhe da dobra no arco de aço inoxidável .014" com objetivo de obter movimento de translação durante fechamento de espaço.
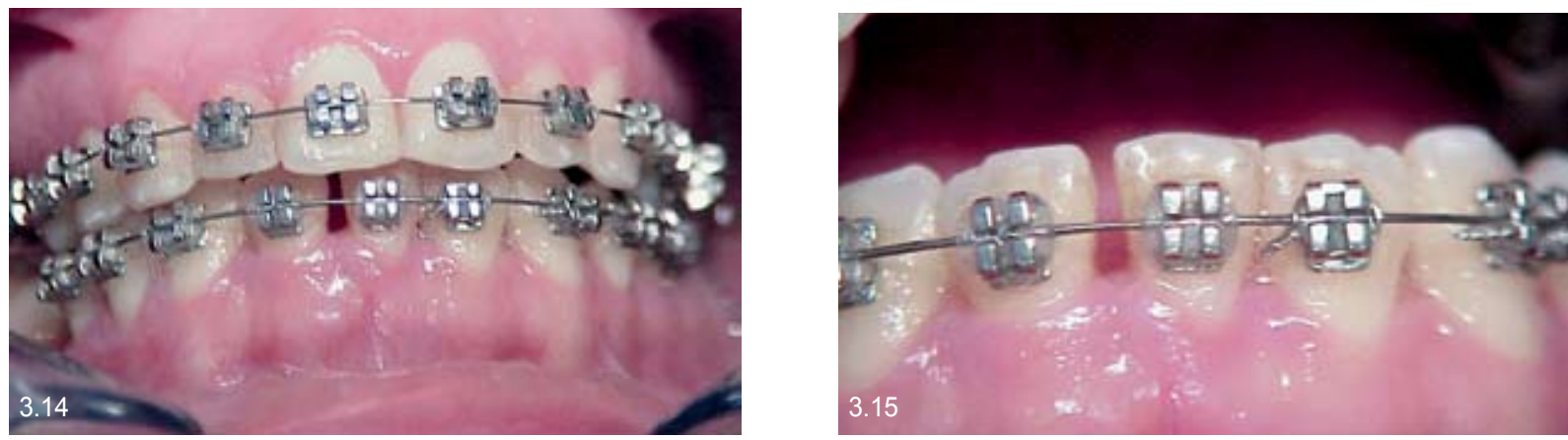

FIGURAS 3.14 e 3.15 - Espaço remanescente após correção do apinhamento.
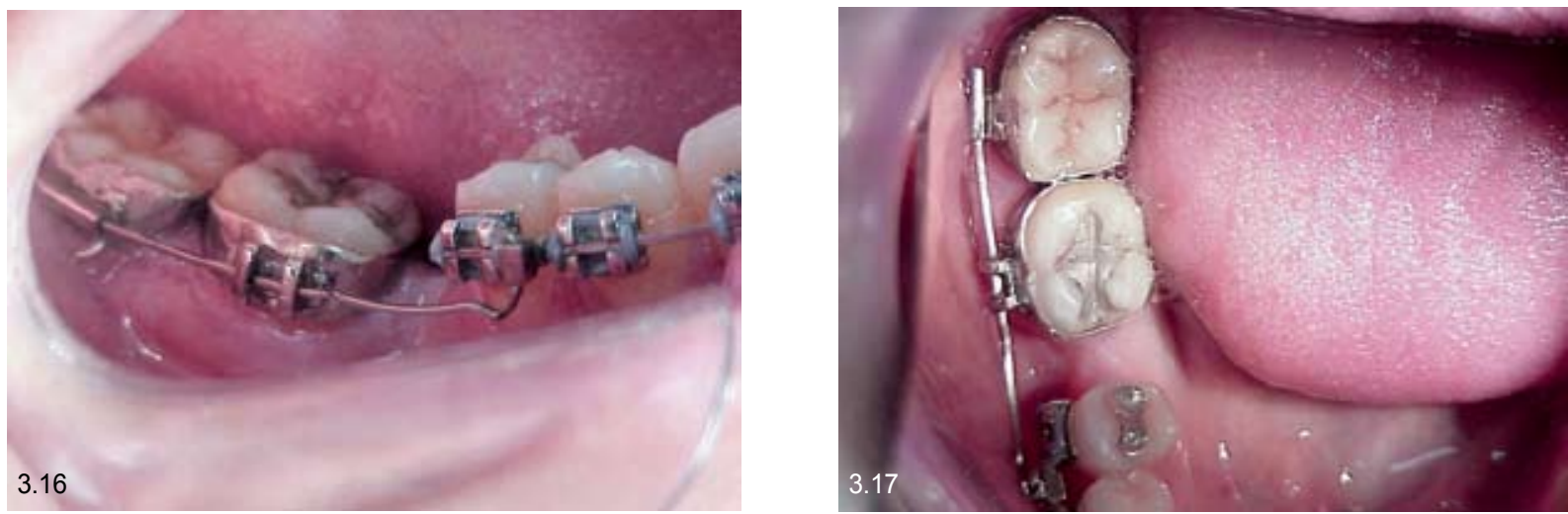

FIGURAS 3.16 e 3.17 - Verticalização dos molares com fio TMA apoiado no tubo de Marcote.
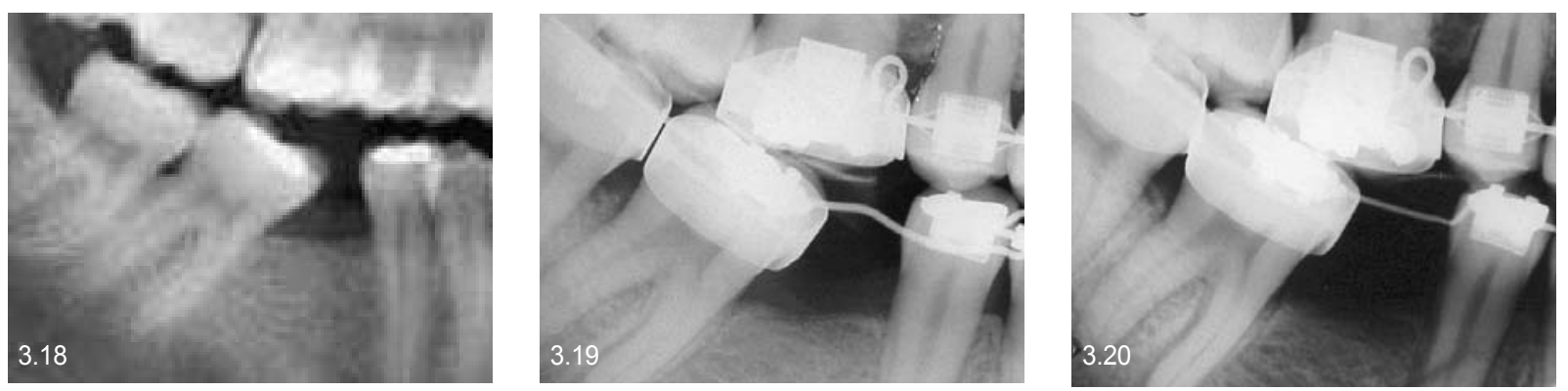

FIGURAS 3.18, 3.19 e 3.20 - Acompanhamento radiográfico durante mecânica de verticalização 


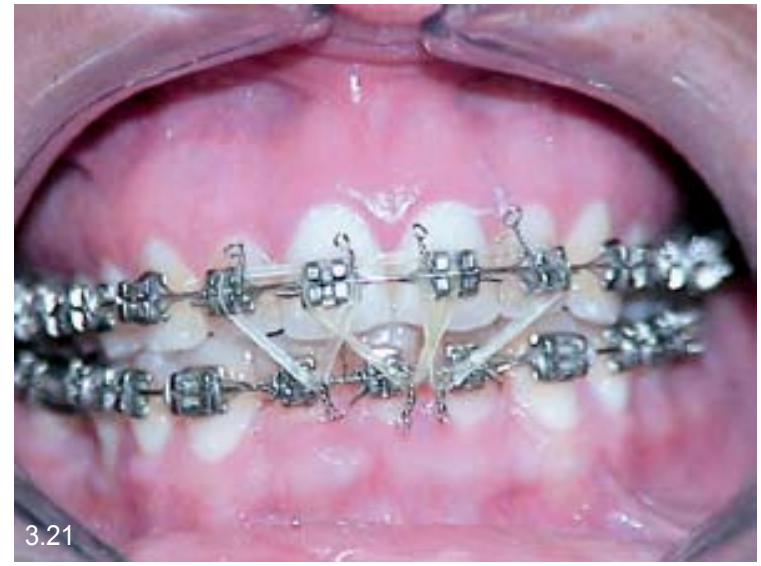

FIGURA 3.21 - Intercuspidação durante fase de finalização.

\section{CONCLUSÃO}

Com base nos aspectos avaliados, presentes na literatura e evidenciados pelos casos clínicos aqui apresentados, pode-se concluir que a extração de um incisivo inferior é uma abordagem terapêutica bastante eficaz em situações criteriosamente selecionadas.

\title{
Mandibular incisor extraction: a terapeutic option
}

\begin{abstract}
The orthodontic treatment strategy in crowded cases has usually been oscillated among no extraction and premolars' extractions. In certain situations the choice for an alternative or another would bring negative consequences. The extraction of a lower incisor in well selected cases represents an efficient approach, although little attention has been given to this kind of therapy in the literature. However, the correct indication must be evaluated by the orthodontist, who needs to know the peculiarities related to this treatment modality. In this sense, the aim of this work is to approach in a systematic way the several clinical aspects related with this therapeutic modality, illustrating its applicability through the presentation of treated cases.
\end{abstract}

Key words: Crowding. Mandibular incisor extaction. Diagnosis.

\section{REFERÊNCIAS}

1. BAHREMAN, A. A. Lower incisor extraction in orthodontic treatment. Am J Orthod, St. Louis, v. 72, no. 5, p. 560-567, Nov. 1977.

2. BERNSTEIN, L. Edward H. Angle versus Calvin S. Case: extraction versus nonextraction. Part l. Historical revisionism. Am J Orthod Dentofacial Orthop, St. Louis, v. 102, no. 5, p. 464-470, Nov. 1992.

3. CANUT, J. A. Extração de incisivo inferior: indicações a avaliação a longo prazo. R Dental Press Ortodon Ortop Facial, Maringá, v. 2, n. 3, p. 48-49, maio/jun. 1997.

4. FAEROVING, E.; ZACHRISON, B. U. Effects of mandibular incisor extraction on anterior occlusion in adults with class III malocclusion and reduced overbite. Am J Orthod Dentofacial Orthop, St. Louis, v. 115, no. 2, p. 113-124, Feb. 1999.

5. JANSON, G. R. P. et al. A importância da individualização no planejamento ortodôntico. R Dental Press Ortodon Ortop Fac, Maringá, v. 8, n. 2, p. 31-45, mar./abr. 1998.

6. KLEIN, D. Incisivo central inferior: uma opção de extração. R Dental Press Ortodon Ortop Facial, Maringá, v. 2, n. 6, p. 42-43, nov./dez. 1997.

7. KOKICH, V. O. Treatment of a class I malocclusion with a carious mandibular incisor and no Bolton discrepancy. Am J Orthod Dentofac Orthop, St. Louis, v. 118, no. 1, p. 107-113, July 2000

8. LIMA, R. S. A administração dos espaços nos arcos dentários na planificação do tratamento ortodôntico. Ortodontia, São Paulo, v. 32, n. 2, p. 95-106, maio/ago. 1999.
9. MERCADANTE, M. M. N. Extrações seriadas. In: FERREIRA, F. V. Diagnóstico e planejamento clínico. 2. ed. São Paulo: Artes Médicas, 1998. p. 171-186.

10. OWEN, A. H. Single lower incisor extraction. J Clin Orthod, Boulder, v. 27, no 3, p. 153-160, Mar. 1993.

11. RIEDEL, R. A.; LITTLE, R. M.; BUI, T. D. Mandibular incisor extraction-postretention evaluation of stability and relapse. Angle Orthod, Appleton, v. 62, no. 2, p. 103-116, 1992.

12. SHERIDAN, J. J.; HASTINS, J. Air-rotor stripping and lower incisor extraction treatment. J Clin Orthod, Boulder, v. 26, no. 1 , p. 18-22, Jan. 1992.

13. VALINOTI, J. R. Mandibular incisor extraction therapy. Am J Orthod Dentofacial Orthop, St. Louis, v.105, no. 2, p. 107-116, Feb. 1994.

Endereço para correspondência

Camilo Massa Ferreira Lima

Endereço: Estrada do Arraial, 3286, sala 12 - Parnamirim -

Recife / PE

CEP: 52051-380.

E-mail: camilomassa@uol.com.br 